\title{
The Role of Hypothalamic NF- $\kappa$ B Signaling in the Response of the HPT-Axis to Acute Inflammation in Female Mice
}

\author{
E. M. de Vries, S. Nagel, R. Haenold, S. M. Sundaram, F. W. Pfrieger, E. Fliers, \\ H. Heuer, and A. Boelen \\ Department of Endocrinology and Metabolism (E.M.d.V., E.F., A.B.), Academic Medical Center, \\ University of Amsterdam, 1105 AZ Amsterdam, The Netherlands; Leibniz Institute on Aging-Fritz \\ Lipmann Institute (S.N., R.H., H.H.), 07745 Jena, Germany; Leibniz Research Institute for Environmental \\ Medicine (S.M.S., H.H.), 40225 Düsseldorf, Germany; and Institute of Cellular and Integrative \\ Neurosciences (F.W.P.), University of Strasbourg, 67084 Strasbourg, France
}

\begin{abstract}
A large proportion of critically ill patients have alterations in the hypothalamus-pituitary-thyroid (HPT) axis, collectively known as the nonthyroidal illness syndrome. Nonthyroidal illness syndrome is characterized by low serum thyroid hormone $(\mathrm{TH})$ concentrations accompanied by a suppressed central component of the HPT axis and persistent low serum TSH. In hypothalamic tanycytes, the expression of type 2 deiodinase (D2) is increased in several animal models of inflammation. Because D2 is a major source of $T_{3}$ in the brain, this response is thought to suppress TRH expression in the paraventricular nucleus via increased local bioavailability of $\mathrm{T}_{3}$. The inflammatory pathway component RelA (the p65 subunit of nuclear factor $-\kappa \mathrm{B}$ ) can bind the Dio2 promoter and increases D2 expression after lipopolysaccharide (LPS) stimulation in vitro. We aimed to determine whether RelA signaling in tanycytes is essential for the LPS-induced D2 increase in vivo by conditional elimination of RelA in tanycytes of mice (RelA $\left.{ }^{\text {ASTKO }}\right)$. Dio2 and Trh mRNA expression were assessed by quantitative in situ hybridization 8 or 24 hours after saline or LPS injection. At the same time points, we measured pituitary $T s h \beta$ mRNA expression and serum $T_{3}$ and $T_{4}$ concentrations. In ReIA ${ }^{\text {ASTKO }}$ mice the LPS-induced increase in Dio2 and decrease in Trh mRNA levels in the hypothalamus were reduced compared with the wild-type littermates, whereas the drop in pituitary Tsh $\beta$ expression and in serum TH concentrations persisted. In conclusion, RelA is essential for the LPS-induced hypothalamic D2 increase and TRH decrease. The central changes in the HPT axis are, however, not required for the down-regulation of $T s h \beta$ expression and serum TH concentrations. (Endocrinology 157: 2947-2956, 2016)
\end{abstract}

$\mathbf{T}$ he nonthyroidal illness syndrome (NTIS) is frequently observed in critically ill patients admitted to the intensive care unit (1). NTIS is characterized by low serum thyroid hormone $(\mathrm{TH})$ concentrations and a suppressed central component of the hypothalamus-pituitary-thyroid (HPT) axis, both in animal models and in humans (2-4). Although often regarded as an adaptive mechanism during acute inflammation, NTIS may negatively influence dis-

\section{ISSN Print 0013-7227 ISSN Online 1945-7170}

Printed in USA

Copyright $@ 2016$ by the Endocrine Society

Received January 14, 2016. Accepted May 11, 2016.

First Published Online May 17, 2016 ease outcome in protracted critical illness. Furthermore, local TH metabolism is differentially affected depending on the timing and tissue studied, making it a difficult and complex syndrome to interpret (2).

The exact mechanism involved in the illness-induced suppression of the HPT axis is incompletely understood. Secretion of TRH from the paraventricular nucleus (PVN) is negatively regulated by $\mathrm{T}_{3}$, thus forming a negative feed-

\footnotetext{
Abbreviations: ARC, arcuate nucleus; D2, type 2 deiodinase; EGFP, enhanced GFP; GFP green fluorescent protein; GLAST, glutamate aspartate transporter; HPT, hypothalamuspituitary-thyroid; $I_{\kappa}-\mathrm{B} \alpha$, Inhibitor of Kappa light chain enhancer in B-cells alpha; LPS, lipopolysaccharide; $M E$, median eminence; NF- $\kappa B$, nuclear factor $-\kappa B$; NTIS, nonthyroidal illness syndrome; PVN, paraventricular nucleus; PPCR, quantitative PCR; SSC, saline sodium citrate buffer; TAM, tamoxifen; TH, thyroid hormone; TRH-DE, TRH degrading ectoenzyme; WT, wild type; YFP, yellow fluorescent protein.
} 
back loop. The main source of $\mathrm{T}_{3}$ in the central nervous system is type 2 deiodinase (D2), an enzyme encoded by the Dio2 gene that converts the prohormone $\mathrm{T}_{4}$ (secreted by the thyroid gland) from the cerebrospinal fluid and the circulation into the biologically active hormone $\mathrm{T}_{3}(5,6)$. D2 is strongly expressed in tanycytes, a specialized glial cell type in the wall of the third ventricle $(7,8)$. During acute inflammation, the expression and activity of D2 in the hypothalamus is up-regulated $(9,10)$ independently of the fall in TH concentrations (11). Increased activity of D2 in tanycytes suppresses TRH secretion from the PVN via local increase in $\mathrm{T}_{3}$ availability in the hypothalamus (9, 12). Mice lacking D2 are unable to adequately suppress TRH expression in response to bacterial endotoxin (lipopolysaccharide [LPS]) (13) and studies in cell specific knock out mice make clear that D2 in tanycytes is essential for proper regulation of the HPT axis (14).

The inflammatory pathway component RelA (the p65 subunit of nuclear factor $-\kappa \mathrm{B}[\mathrm{NF}-\kappa \mathrm{B}]$ ) was reported to increase D2 expression in vitro (15) and to bind to the Dio2 promoter region (16). We recently showed that RelA is up-regulated in vivo in the mediobasal hypothalamus of mice after LPS administration and that inhibition of RelA in a primary tanycyte culture prevents the LPS induced increase of Dio2 mRNA expression (17). However, evidence for a causal role for RelA in the regulation of D2 during acute inflammation in vivo is still missing.

We aimed to address this question using temporally controlled tanycyte-specific elimination of RelA. To this end, we crossed RelA flox mice with mice expressing a tamoxifen (TAM)-inducible Cre recombinase $\left(\mathrm{CreER}^{\mathrm{T} 2}\right.$ ) under the control of the glutamate aspartate transporter (GLAST) promoter. Acute inflammation was induced by LPS injection. Illness-induced hypothalamic Dio2 and Trh expression was determined by in situ hybridization. In addition, pituitary Tsh $\beta$ mRNA expression and serum TH were measured using quantitative PCR (qPCR) and a RIA, respectively.

\section{Materials and Methods}

\section{Animals}

Animals were kept under controlled conditions in a pathogenfree environment and provided with food and water ad libitum. All animal interventions were performed in accordance with the European Convention for Animal Care and Use of Laboratory Animals and were approved by the local ethics committee. Conditional RelA flox mice were a kind gift of Roland M. Schmid (Technical University Munich, Munich, Germany) (18). To target tanycytes, transgenic mice with a GLAST-controlled CreERT2 expression were used (19). Mice were backcrossed to a C57BL/6 (B6) background for at least 10 generations. A GLAST-
CreERT $^{2}$-YFP reporter mouse (20) was used to verify TAMinduced Cre expression in tanycytes. A NF- $\kappa \mathrm{B}$-enhanced green fluorescent protein (EGFP)-reporter mouse (21), expressing EGFP under the control of an artificial NF- $\kappa \mathrm{B}$-responsive promoter was used to verify LPS induced activation of RelA signaling in tanycytes. Male and female NF- $\kappa$ B-EGFP-reporter mice received an ip injection of $10 \mu \mathrm{g}$ LPS per gram of body weight (LPS, Escherichia coli O127:B8; Sigma) diluted in $0.9 \% \mathrm{NaCl}$. Control mice received $0.9 \% \mathrm{NaCl}(\mathrm{n}=2-3$ mice per group). Mice were perfused transcardially with $1 \times$ PBS followed by $4 \%$ paraformaldehyde/PBS. Brains were collected and postfixed in $4 \%$ paraformaldehyde for 24 hours at $4{ }^{\circ} \mathrm{C}$. After postfixation, the brains were cryoprotected by immersion in $30 \%$ sucrose/PBS at $4^{\circ} \mathrm{C}$. Thirty-micrometer coronal brain sections were cut on a cryostat (Leica CM 3050s). Serial sections were collected free floating in PBS.

Female mice (7-14 wk of age) with a homozygous Cre/loxPbased deletion of relA alleles (RelA ${ }^{\text {flff } ; t g /+}$, designated as

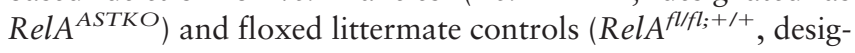
nated as wild type [WT]) were used. Cre recombination was induced by five consecutive ip injections (once every $24 \mathrm{~h}$ ) of 80 $\mathrm{mg}$ tamoxifen per kilogram of body weight, applied at a concentration of $10 \mathrm{mg} / \mathrm{mL}$ in an oil/ethanol (9:1) solution, between 30 and 50 days of age $(19,22)$. Efficient recombination was verified by genotyping showing the expression of a truncated relA transcript after tamoxifen treatment. Acute inflammation was induced by an ip injection of $10 \mu \mathrm{g}$ LPS per gram of body weight diluted in $0.9 \% \mathrm{NaCl}$. Control mice received $0.9 \% \mathrm{NaCl}$. Mice ( $\mathrm{n}=8-10$ mice per group) were killed by $\mathrm{CO}_{2}$ intoxication 8,24 , or 36 hours after LPS administration, respectively. To control for diurnal variation, each time point had its own control group and all experiments were done at the same time of day. Blood was taken by heart puncture, and serum was stored at $-20^{\circ} \mathrm{C}$. Brains were isolated, snap frozen in dry ice-cooled 2 -methyl butane and cut with a cryostat in 20- $\mu$ m-thick sections. Pituitaries were isolated, frozen on dry ice, and stored at $-80^{\circ} \mathrm{C}$ for RNA isolation.

\section{Genotyping}

Tail biopsies were incubated overnight at $55^{\circ} \mathrm{C}$ in $300 \mu \mathrm{L}$ PCR buffer $(50 \mathrm{mM} \mathrm{KCl} ; 10 \mathrm{mM}$ Tris- $\mathrm{HCl}, \mathrm{pH} 8.3 ; 2.5 \mathrm{mM}$ $\mathrm{MgCl}_{2} ; 0.1 \mathrm{mg} / \mathrm{mL}$ gelatin; $0.45 \%$ [vol/vol] Nonidet-P40; $0.45 \%$ [vol/vol] Tween 20) containing $40 \mu \mathrm{g}$ proteinase $\mathrm{K}$ (Merck) while shaking. After incubation, samples were heated for 10 minutes at $95^{\circ} \mathrm{C}$ to inactivate the proteinase K. Samples were spun down for 5 minutes and the supernatant was used for subsequent PCRs. Blood samples were taken to test for recombination in peripheral immune cells that could potentially affect the LPS response in knockout mice. PCRs to detect floxed $\left(\operatorname{Rel}^{\text {flox }}\right)$ and recombined $\left(\operatorname{RelA}^{\text {del }}\right)$ RelA alleles as well as the Cre recombinase transgene were performed using the following parameters and primers: 4 minutes at $94^{\circ} \mathrm{C}\left(45 \mathrm{sec}\right.$ at $94^{\circ} \mathrm{C}, 30 \mathrm{sec}$ at $58^{\circ} \mathrm{C}, 45 \mathrm{sec}$ at $\left.72^{\circ} \mathrm{C}\right) 35$ times, 5 minutes at $72^{\circ} \mathrm{C}$. Primers included the following: RelA flox forward, $5^{\prime}$-GAGCGCATGC CTAGCACCAG-3', RelA ${ }^{\text {flox }}$ reverse, 5'-GTGCACTGCATGC GTGCAG-3'; RelA ${ }^{\text {del }}$ forward, 5'-AGTGCACTGCATGCG TGCAG-3', RelAdel reverse, 5'-GTGCACTGCATGCGTG CAG-3'; Cre forward, 5'-GCCTGCATTACCGGTCGATGCA ACGA-3', Cre reverse, 5'-GTGGCAGATGGCGCGGCAACA CCATT-3', control $(C \beta)$ : forward, 5'-CACTGATGTTCTGTG 
TGACA-3', reverse, 5'-GAGGATCTGAGAAATGTGACTCC AC-3'. PCR fragments were analyzed on DNA agarose gel.

\section{Confirmation of conditional knockout}

To confirm expression of recombined RelA transcripts in the target area, the periventricular area containing the tanycyte layer was punched in RNAlater buffer (Life Technologies), and RNA was isolated as described below. Expression of the wild-type and recombined mRNA was confirmed by qPCR with the following primers: RelA forward, 5' -tgacccetgtcctctcacat- $3^{\prime}$ and RelA reverse, 5' -gacacaccctggttcaggag- $3^{\prime}$. The qPCR resulted in the amplification of a 922-bp PCR product for WT RelA transcripts, and a 448-bp PCR product for recombined RelA transcripts.

\section{Immunohistochemistry}

For visualizing yellow fluorescent protein (YFP) in tanycytes of GLAST-CreERT ${ }^{2}$-YFP reporter mice, perfusion-fixed brains were cut on a vibratome. Sections were blocked as well as permeabilized with $10 \%$ normal goat serum in $0.2 \%$ Triton X-100 containing PBS. Immunostaining was performed using a rabbit antigreen fluorescent protein (GFP) antibody (1:500; Molecular Probes). Sections were then incubated with fluorescence-labeled secondary antibodies (1:1000, Alexa Fluor 488; Invitrogen) and analyzed using an Olympus AX70 microscope.

For visualizing EGFP in tanycytes of LPS and saline injected NF- $\kappa$ B-EGFP-reporter mice, sections were washed in PBS followed by permeabilization with $0.2 \%$ Triton X-100. After permeabilization, sections were blocked using 3\% normal goat serum, followed by overnight incubation with the GFP antibody (1:500, catalog number GFP-1020; Aves) at $4^{\circ} \mathrm{C}$. Sections were washed in PBS and incubated with secondary antibody-biotinylated goat antichicken IgY (1:500, catalog number ab 6876; Abcam) for 1 hour at room temperature. Subsequently, sections incubated with a complex of avidin and biotin (1.50, Vectastain $\mathrm{ABC}$ kit, catalog number PK-6101) and then covered with 3,3'diaminobenzidine- $\mathrm{H}_{2} \mathrm{O}_{2}$ solution (one tablet set for $5 \mathrm{~mL}$ of deionized water, catalog number D4293; Sigma). After stopping the color reaction with PBS, sections were mounted on coated slides, air dried overnight, and coverslipped using cytoseal XYL mounting medium (catalog number 8312-4; Thermo Scientific,). Staining was visualized with the Axio Imager 2 microscope (Carl Zeiss).

\section{Riboprobe synthesis}

A cDNA fragment of mouse Tr $h$ cDNA corresponding to nt 1251-1876 (GenBank accession number NM_009426.2) and a fragment of mouse Dio2 cDNA corresponding to nt 131-1045 (GenBank accession number AF096875) were generated by PCR and subcloned into the pGEM-T Easy Vector (Promega).

Radiolabeled riboprobes for Dio2 and Trh were generated by performing the transcription reaction in the presence of $\left[{ }^{35}\right.$ S $]$ uridine 5-triphosphate (Hartmann Analytik) as described before (23).

\section{In situ hybridization}

In situ hybridization was carried out as described before (24). Slides were fixed in $4 \%$ paraformaldehyde solution. After washes in PBS, slides were permeabilized in $0.4 \%$ Triton-X-100 in PBS. Deacetylation was carried out by incubating the slides in $0.1 \mathrm{M}$ triethanolamine ( $\mathrm{pH} 8$ ) containing $0.25 \%$ ( $\mathrm{vol} / \mathrm{vol}$ ) acetic anhydride for 10 minutes. Slides were washed in PBS, dehydrated in increasing ethanol concentrations, and air dried.

Radiolabeled riboprobes were diluted to a final concentration of $1 \times 10^{4} \mathrm{cpm} / \mu \mathrm{L}(\operatorname{Tr} h)$ or $5 \times 10^{4} \mathrm{cpm} / \mu \mathrm{L}$ (Dio2) in hybridization buffer $(50 \%$ formamide; $10 \%$ dextran sulfate; $0.6 \mathrm{M}$ $\mathrm{NaCl} ; 10$ mM Tris/HCl, pH 7.4; 1× Denhardt's solution; 100 $\mathrm{mg} / \mathrm{mL}$ sonicated salmon sperm DNA; $1 \mathrm{mM}$ EDTA-di-Na; and $10 \mathrm{mM}$ dithiothreitol). TRH was diluted with $5 \%$ cold probe. After application of the hybridization mixture, slides were coverslipped and incubated overnight at $58^{\circ} \mathrm{C}$. The next morning, slides were washed in $2 \times$ saline citrate buffer (SSC) and coverslips were removed. Subsequently, slides were washed in $1 \times$ SSC and treated with ribonuclease $\mathrm{A}(20 \mu \mathrm{g} / \mathrm{mL})$ and ribonuclease T1 $(1 \mathrm{U} / \mathrm{mL})$ at $37^{\circ} \mathrm{C}$ for 30 minutes. Successive washes followed at room temperature in $1 \times, 0.5 \times$, and $0.2 \times$ SSC for 20 minutes each and in $0.2 \times \mathrm{SSC}$ at $60^{\circ} \mathrm{C}$ for 1 hour. The sections were dehydrated and exposed to Biomax MR film (Kodak). Sections were exposed for 1 day (Trh) or 3 days (Dio2). Integrated density of the signal in the PVN (for Trb) and the arcuate nucleus (ARC)median eminence (ME) region (for Dio2) was determined using ImageJ software (National Institutes of Health, Bethesda, Maryland). A value per brain section was calculated by subtracting the background signal and by dividing the outcome by the area of the calculated signal.

\section{RNA isolation and qPCR}

Pituitary mRNA was isolated on the MagnaPure RNA isolation system using the LC mRNA tissue kit (Roche Molecular Biochemicals). cDNA was synthesized with the first-strand cDNA synthesis kit with oligodeoxythymidine primers (Roche Molecular Biochemicals). Quantitative PCR was performed using the Lightcycler 480 and Lightcycler480SybrGreen I master mix (Roche Molecular Biochemicals). Primers used for detection of Hprt, Dio2, and Tsh $\beta$ are described elsewhere (9). Primers for cyclophilin-B (Ppib) were: forward, 5'-GAGACTTCACCAG GGG-3', and reverse, 5'-CTGTCTGTCTTGGTGCTCTCC-3'.

Primers for elongation factor 1-a1 (Eef1a1): forward, 5'AGTCGCCTTGGACGTTCTT-3'， reverse， 5'-ATTTGTA GATCAGGTGGCCG-3'. Quantification was performed using the LinReg software. Samples deviating more than $5 \%$ from the mean efficiency value of the assay were excluded. Calculated values were normalized to the geometric mean of three reference genes (HPRT, cyclophilin, EF1a1) according to the Minimum Information for Publication of Quantitative Real-Time PCR Experiments guidelines. Reference gene expression was not significantly different among treatment groups.

\section{$\mathrm{T}_{3}$ and $\mathrm{T}_{4}$ measurements}

$\mathrm{T}_{3}$ and $\mathrm{T}_{4}$ serum concentrations were measured with an in house RIA (25). All samples of one experiment were measured within the same assay (intraassay variability $\mathrm{T}_{3}, 3.6 \%$, and $\mathrm{T}_{4}$, $6.6 \%)$.

\section{In vitro dual-luciferase assay}

To test whether inhibition of RelA can have a direct effect on the Dio 2 promoter, we designed an in vitro dual luciferase approach. An H4 human glioma cell line was acquired from American Type Culture Collection and grown in DMEM supplemented with $10 \%$ fetal calf serum and $1 \%$ penicillin-streptomycin-fungizone (all from Lonza). Cells $\left(5 \cdot 10^{4}\right.$ per well) were 


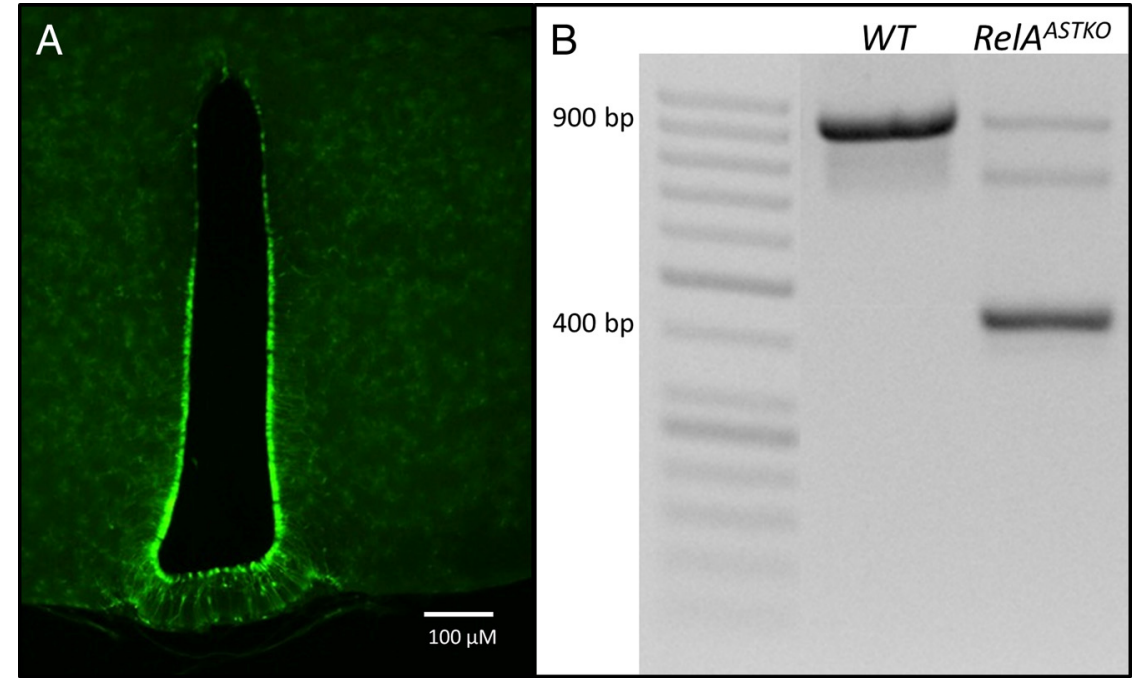

Figure 1. A, Immunofluorescence image of the tamoxifen-induced Cre mediated YFP expression in the tanycyte layer lining the hypothalamic third ventricle. B, Analysis of RelA PCR products from the circumventricular area of WT and RelA ${ }^{\text {ASTKO }}$ mice. The 922-bp product represents WT RelA, and the 448-bp band represents truncated RelA.

seeded in a 24-well plate and were transfected with 250 ng PGL3hdio2-luc construct (kindly provided by B. Gereben, Hungarian Academy of Sciences, Budapest, Hungary) and 4 ng P3xflagCMV-Renilla (kindly provided by M. Vooijs, Maastricht University, Maastricht, The Netherlands) using Jetprime transfection reagent and buffer according to the manufacturer's guidelines (Polyplus Transfection SA). After 24 hours, cells were stimulated with $1 \mu \mathrm{g} / \mathrm{mL}$ LPS. To inhibit NF- $\kappa$ B nuclear translocation, cells were treated with JSH-23 (50 $\mu \mathrm{M}$, dissolved in $10 \%$ dimethylsulfoxide; Calbiochem), or with dimethylsulfoxide alone. After 4 hours, cells were washed with PBS and lysed with passive lysis buffer from the dual-luciferase reporter assay kit (Promega). A dual-luciferase assay was performed according to the manufacturer's instructions, and the samples were analyzed using a Glomax luminometer (Promega).

\section{Statistics}

Differences between conditions were evaluated per time point using a two-way ANOVA with two grouping factors (treatment and genotype). To evaluate the response to LPS, data were normalized to saline controls, and a two-way ANOVA with two grouping factors (time and genotype) was performed. Normal distribution of the data was tested using the Shapiro-Wilk test on the residues of the ANOVA. $P$ values in the figures represent the effect of LPS treatment (Ptreat) or genotype (Pgenotype). To test pair-wise comparisons, an ANOVA was followed by a Tukey's post hoc test. Symbols in the figures represent the pair-wise $P$ values. All tests were performed using GraphPad Prism 6 (GraphPad software Inc).

\section{Results}

\section{Characterization of the mouse model}

To visualize TAM-induced Cre expression within periventricular tanycytes, GLAST-CreER ${ }^{\mathrm{T} 2}$ mice were crossed to a YFP reporter line (20). Treatment of mice with
TAM resulted in a pronounced expression of Cre recombinase in tanycytes, as indicated by abundant expression of YFP protein in the wall of the third ventricle and median eminence of GLAST-CreER ${ }^{\mathrm{T} 2}$-YFP reporter mice (Figure 1A).

To test for efficient recombination of the RelA locus in periventricular astrocytes and tanycytes of RelA $^{\text {ASTKO }}$ mice, GLAST-CreER ${ }^{\mathrm{T} 2}$ mice were crossed with RelA flox mice and expression of recombined RelA transcripts was analyzed by PCR amplification. Truncated RelA was expressed in periventricular tissue samples comprising the wall of the third ventricle of RelA ${ }^{A S T K O}$ mice but not in tissue samples derived from WT mice (Figure 1B), which showed solid expression levels for full-length RelA transcripts. Moreover, white blood cells of RelA ${ }^{A S T K O}$ mice did not show recombination of RelA implicating that these peripheral immune cells are not affected by TAM induced RelA deletion (data not shown).

\section{LPS-induced acute inflammation leads to NF- $\kappa$ B activation in tanycytes}

To demonstrate activation of the NF- $\kappa \mathrm{B}$ signaling pathway in periventricular tanycytes under inflammatory conditions, we used a recently generated NF- $\kappa$ B-reporter mouse, in which expression of EGFP is under transcriptional control of NF- $\kappa \mathrm{B}(21)$. Analysis of periventricular tissue sections revealed robust expression of EGFP in tanycytes lining the third ventricle 24 hours after LPS injection (Figure 2, A and B). In contrast, in NF- $\kappa$ B-reporter mice receiving saline, no NF- $\kappa \mathrm{B}$ activation was observed (Figure 2C). Thus, acute inflammation induced by LPS administration leads to immediate activation of NF- $\kappa$ B signaling in tanycytes.

\section{Knockdown of RelA in tanycytes prevents the LPS induced D2 increase in the mediobasal hypothalamus and the TRH decrease in the PVN}

LPS administration resulted in a 2-fold increase in Dio2 mRNA expression in the mediobasal hypothalamus of WT mice compared with saline-treated WT mice but not in the mediobasal hypothalamus of RelA ${ }^{A S T K O}$ mice (Figure $3 \mathrm{~A})$ compared with saline-treated RelA ${ }^{A S T K O}$ mice (basal Dio2 levels, however, might be slightly but not significantly elevated in RelA ${ }^{A S T K O}$ mice compared with WT 

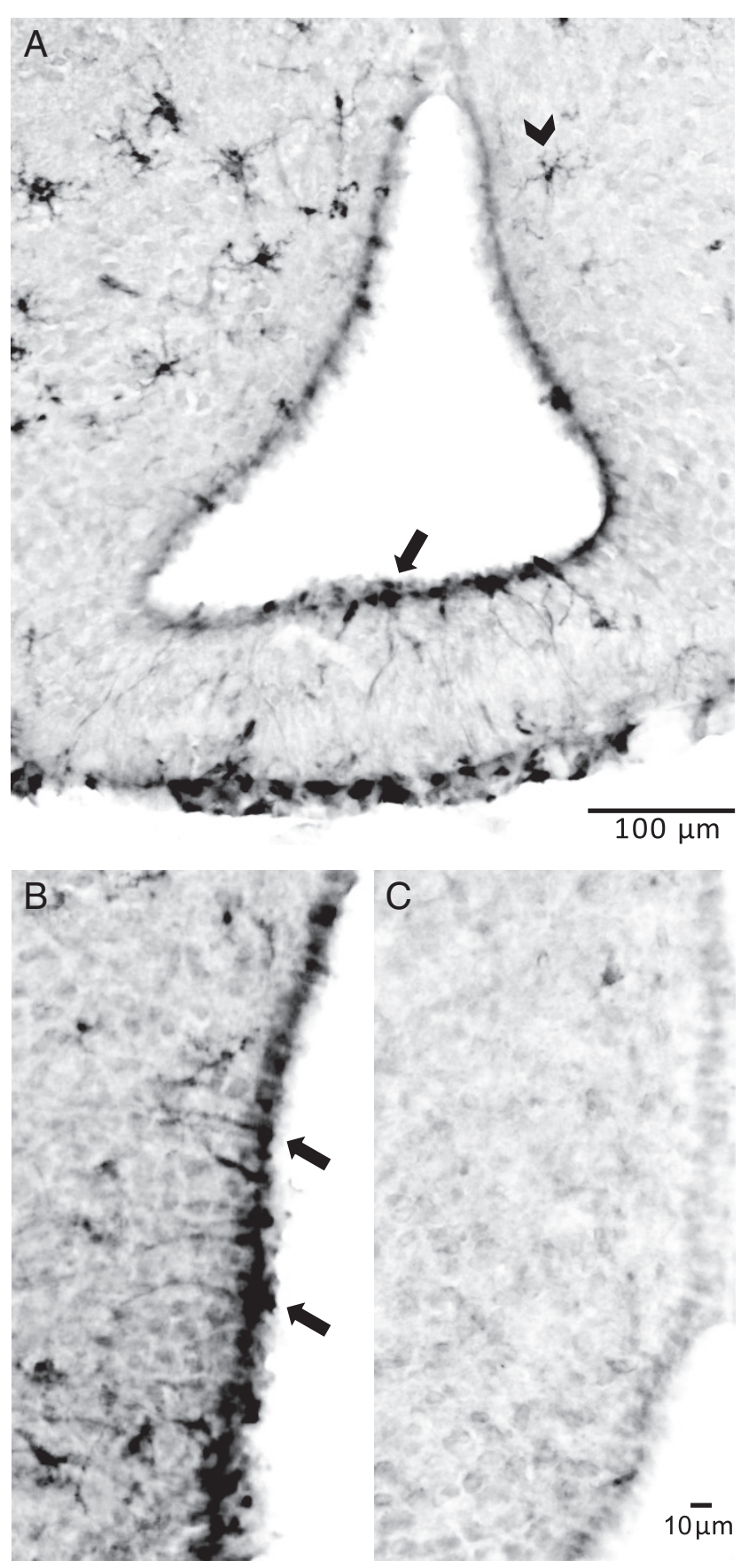

Figure 2. Microscopic image of the third ventricle of LPS (A and B) and saline-injected (C) NF- $\kappa$ B-EGFP-reporter mice are shown.

Magnification, $\times 10(A)$ and $\times 40$ ( $B$ and $C)$. EGFP expression was visualized with 3,3'-diaminobenzidine staining. Arrows indicate representative activated tanycytes, whereas arrowheads point to EGFPpositive microglial cells.

mice). The response was less pronounced after 24 hours (Figure 3A). The relative increase of Dio2 in response to LPS was absent in mice lacking RelA. Trh expression in the PVN decreased 8 hours after LPS administration in the WT mice but not in the RelA ${ }^{A S T K O}$ mice compared with saline-treated mice, and no differences were observed after 24 hours (Figure 3B). Basal Trh expression was signifi- cantly lower in the RelA ${ }^{A S T K O}$ mice compared with WT mice. In summary, the LPS-induced Trh decrease was absent in RelA ${ }^{A S T K O}$ mice.

\section{The effect of RelA knockdown on basal Dio2 and Trh expression is not a direct effect on the Dio2 promoter}

Because we observed a trend toward increased basal Dio2 expression and a decreased basal Trh expression in the RelA ${ }^{A S T K O}$ mice compared with WT mice, we wondered whether the inhibition of RelA function has a direct effect on the Dio2 promoter. We therefore tested the effect of the RelA inhibitor JSH-23 (retains RelA in the cytoplasm, thereby inhibiting the activity) on promoter activity of a human Dio2 promoter construct in human $\mathrm{H} 4$ glioma cells using a dual-luciferase assay. LPS slightly increased Dio 2 promoter activity after 4 hours, whereas JSH-23 decreased basal promoter activity (Figure 4). This was, however, marginal compared with the 300 -fold increase we observed after forskolin stimulation (data not shown).

\section{Knockdown of RelA in tanycytes does not affect Tsh $\beta$ and Dio2 mRNA expression in the pituitary}

Pituitary Tsh $\beta$ mRNA expression decreased 24 hours after LPS administration to a similar extent in both WT and RelA ${ }^{A S T K O}$ mice (Figure 5, A-C). Pituitary Dio2 mRNA expression was increased $8 \mathrm{~h}$ ours after LPS injection in the WT but not in the RelA ${ }^{A S T K O}$ mice, and it significantly decreased 24 hours after LPS injection in WT mice (Figure 5, D-F).

\section{Knockdown of RelA in tanycytes does not affect the LPS-induced decrease in serum $T_{3}$ and $T_{4}$}

LPS injection had pronounced effects on serum TH concentrations. Serum $\mathrm{T}_{4}$ decreased to a similar extent 8 , 24, and 36 hours after LPS injection in the WT and RelA ${ }^{\text {ASTKO }}$ mice (Figure 6, A-D). Serum $\mathrm{T}_{3}$ decreased 24 and 36 hours after the LPS administration, and the observed decrease was similar in both genotypes (Figure 6, E-H).

\section{Discussion}

In the present study, we show the importance of the classical NF- $\kappa$ B pathway, and specifically RelA, in the inflammation-induced Dio 2 expression in tanycytes. To this end, we used a tamoxifen-inducible conditional knockout mouse that lacks RelA specifically in astrocytes and tanycytes. In mice carrying the inducible GLAST-CreER ${ }^{\mathrm{T} 2}$ transgene, Cre-recombinase activity showed a high ta- 
A ARC-ME D2 expression $t=8$
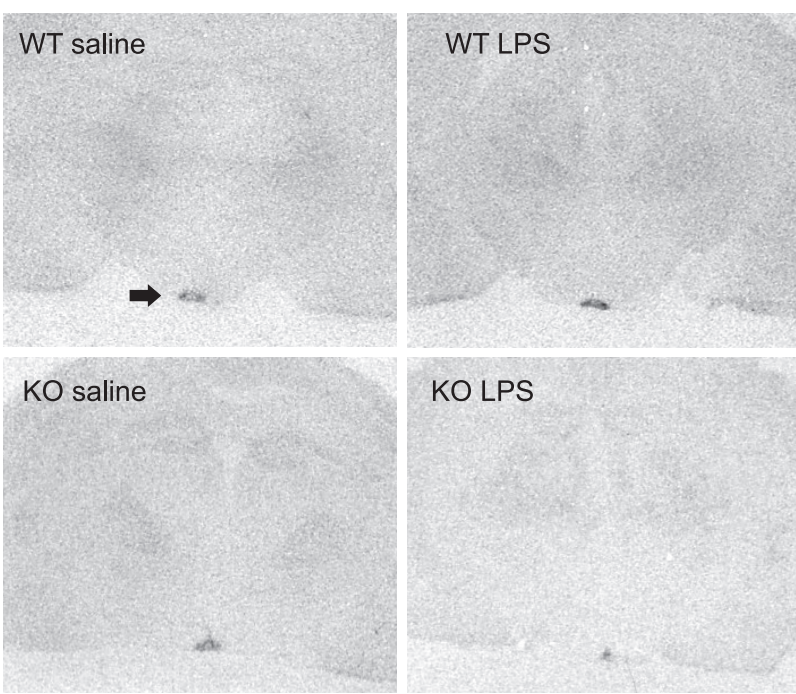

KO LPS

B

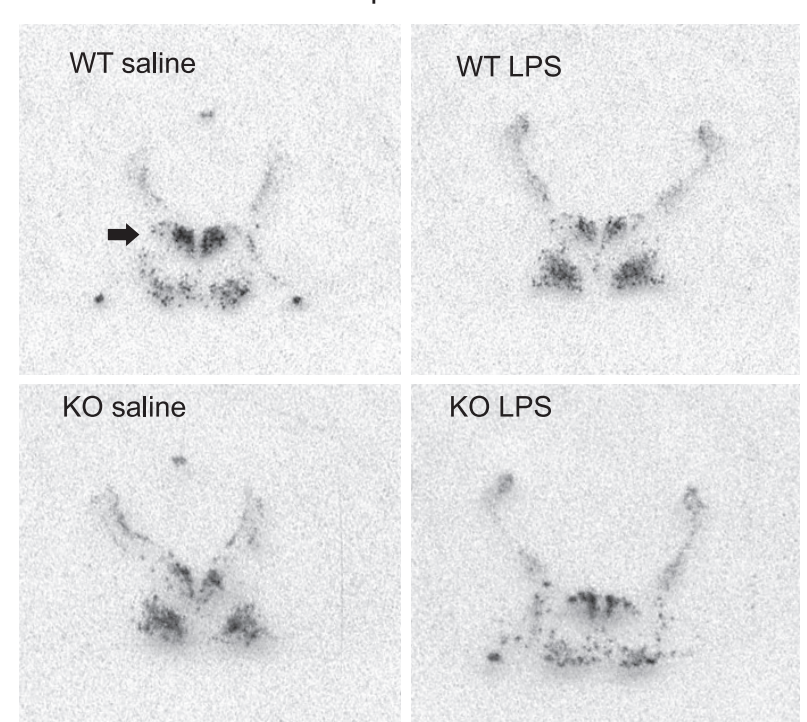

$8 \mathrm{~h}$
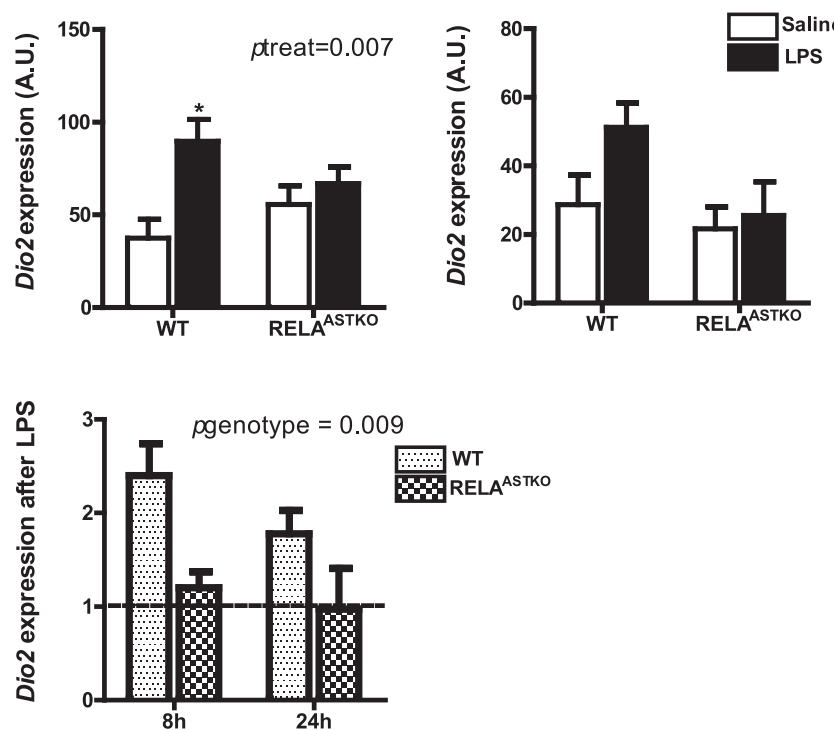

Figure 3. A, Expression of Dio 2 mRNA in the ARC-ME area (dotted lines) 8 and 24 hours after LPS injection. B, Expression of Trh in the PVN 8 and 24 hours after LPS injection. Shown are representative autoradiography pictures of coronal brain sections at 8 hours after injection and the quantification of the signal measured as the integrated density. White bars represent saline-injected mice, and black bars represent LPS-injected mice (10 $\mu \mathrm{g} / \mathrm{g}$ body weight). In the lower graphs, relative responses to LPS injection of WT (dotted bars) and RelA ${ }^{\text {ASTKO }}$ (checked bars) mice is presented. Dotted line represents the saline-treated groups. Mean values \pm SEM are depicted. $P$ values indicate the effect of LPS injection (Ptreat) and genotype (Pgenotype) as evaluated by a two-way ANOVA. Differences between groups ( $\mathrm{n}=5-7$ mice per group) were analyzed post hoc with Tukey's test. ${ }^{*}, P \leq .05 ;{ }^{* *}, P \leq .01 ; b, P \leq .01 . \mathrm{KO}$, knockout.

moxifen responsiveness, particularly in the wall of the third ventricle. In a GLAST-CreER ${ }^{\mathrm{T} 2}$ YFP reporter line, GLAST-driven Cre expression has been recently described to be primarily present in the $\alpha$-subset of tanycytes (26), lining the lower part of the ventricular zone adjacent to hypothalamic nuclei. Although we also detected some Cre-recombinase expression in the $\beta$-subset lining the $\mathrm{ME}$ and infundibulum, we observed the most pronounced expression in $\alpha$-tanycytes. Crossing the GLAST-CreER ${ }^{\mathrm{T} 2}$ mice with RelA ${ }^{\text {flox }}$ mice led to specific expression of truncated RelA in the ventricular walls, in which the tanycytes are located.

We showed before that stimulation of primary tanycyte cultures with LPS leads to rapid phosphorylation, nuclear translocation, and thereby activation of RelA (17). In the present study using a NF- $\kappa \mathrm{B}$ reporter mouse, we show in vivo that LPS-mediated acute inflammation induces target gene expression by the transactivation of NF- $\kappa \mathrm{B}$ specifi- 


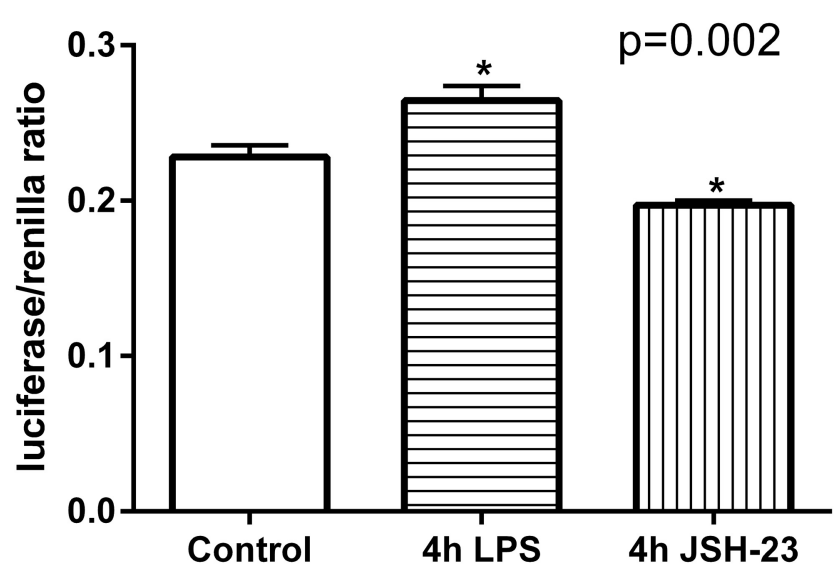

Figure 4. Luciferase to renilla ratios in $\mathrm{H} 4$ glioma cells. $\mathrm{H} 4$ cells were transfected with the hDio2-luc construct and a p3xflag-renilla construct to correct for transfection efficiency. Cells were stimulated with LPS $(1 \mu \mathrm{g} / \mathrm{mL})$ and the RelA nuclear translocation inhibitor JSH-23 $(50 \mu \mathrm{M})$ for 4 hours, followed by a dual-luciferase assay. ${ }^{*}, P \leq .05$.

cally in tanycytes. Additionally, histological/morphological data suggest activation of NF- $\kappa \mathrm{B}$ in microglia in the hypothalamic area.

\section{Role of RelA in Dio2 regulation}

Acute inflammation induced by LPS administration is known to markedly increase Dio2 mRNA expression in the ARC-ME region of the hypothalamus of mice and rats $(9,10)$. In mice lacking RelA in tanycytes, the response of Dio2 expression to LPS was blunted. RelA has been considered a likely candidate for the regulation of $\mathrm{D} 2$ during inflammation because it is able to activate the Dio2 promoter in vitro $(10,16)$. In addition, we recently showed that RelA regulates the LPS-induced Dio 2 mRNA increase in a primary tanycyte cell culture (17). The present study reveals that this is also the case during the acute-phase response in vivo. The NF- $\kappa \mathrm{B}$ protein family consists of several subunits of which RelA acts as a transcriptional activator that forms hetero- and homodimers. In the cytoplasm, NF- $\kappa$ B is bound to Inhibitor of Kappa light chain enhancer in B-cells alpha $(\mathrm{I} \kappa \mathrm{B} \alpha)$, an inhibitory molecule. Upon activation of the signaling cascade, $\mathrm{I} \kappa-\mathrm{B} \alpha$ is phosphorylated by $\mathrm{I} \kappa-\mathrm{B}$ kinase, and NF- $\kappa \mathrm{B}$ is released. NF- $\kappa \mathrm{B}$ can then translocate to the nucleus and activate transcription of target genes (27). The expression of $\mathrm{I} \kappa-\mathrm{B} \alpha$ is also positively regulated by NF- $\kappa \mathrm{B}$ and has been used as a marker for NF- $\kappa \mathrm{B}$ transcriptional activity. A previous study showed that ikba mRNA increased 12 hours after LPS administration secondary to the rise in Dio2 expression (28), suggesting that NF- $\kappa \mathrm{B}$ is not primarily involved

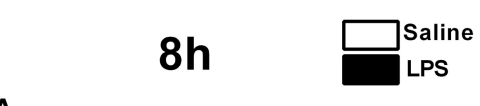

A
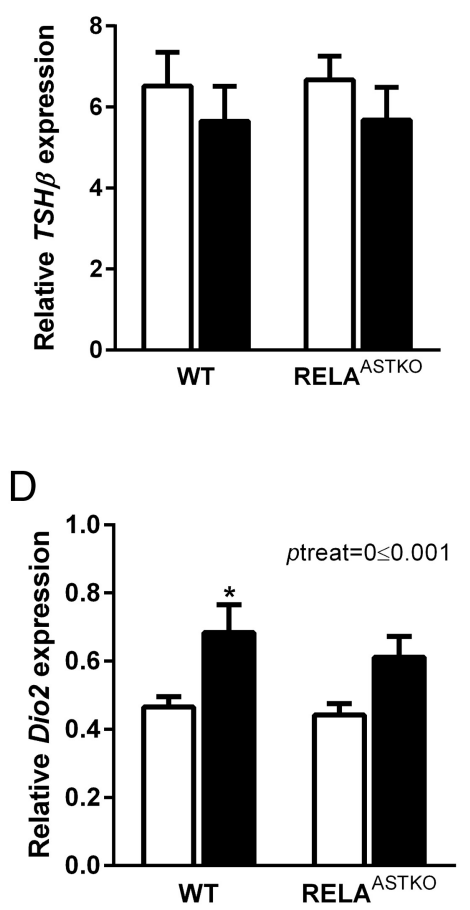

24h

B

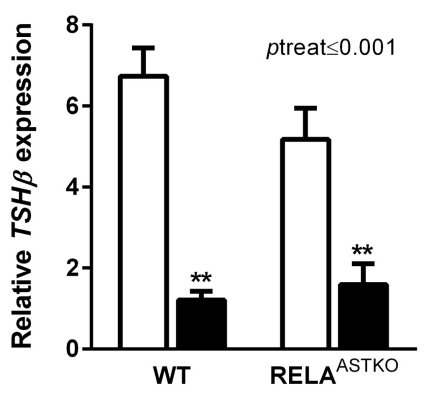

E

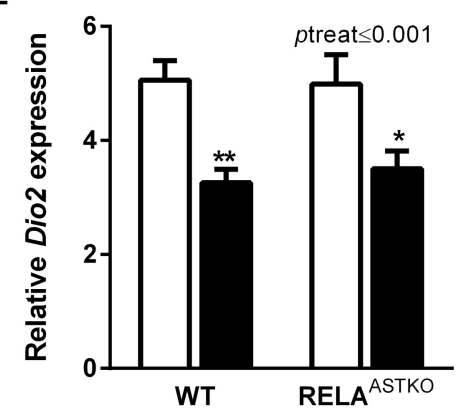

C

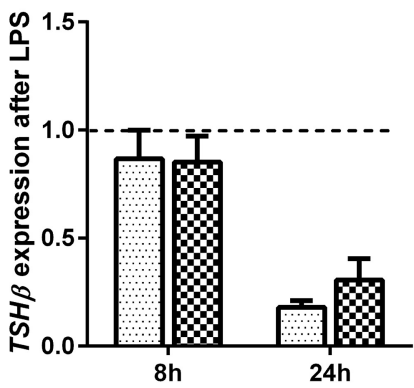

$\mathrm{F}$

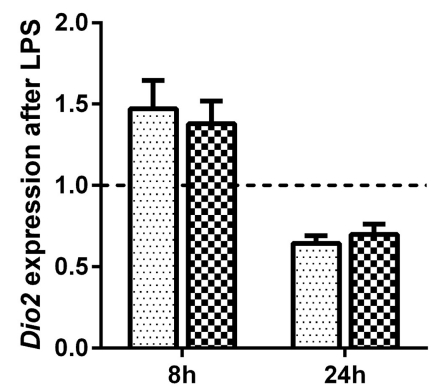

Figure 5. Expression of Tsh $\beta$ mRNA in the pituitary 8 (A) and 24 hours (B) after LPS or saline injection. Expression of Dio 2 mRNA in the pituitary 8 (D) and 24 hours (E) after LPS or saline injection. White bars represent saline-injected mice, and black bars represent LPS-injected mice (10 $\mu$ g/g body weight). In the right panels, relative responses to LPS injection of WT (dotted bars) and RelA ${ }^{A S T K O}$ (checked bars) mice are presented. Dotted line represents the saline-treated groups. Mean values \pm SEM are depicted. $P$ values indicate the effect of LPS injection ( $P$ treat) and genotype (Pgenotype) as evaluated by a two-way ANOVA. Differences between groups ( $\mathrm{n}=5-10$ mice per group) were analyzed post hoc with a Tukey's test. *, $P \leq .05 ; * *, P \leq .01 ; a, P \leq .05$. 
$8 \mathrm{~h}$

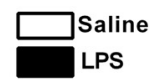

A

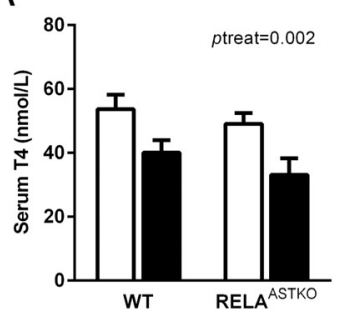

E

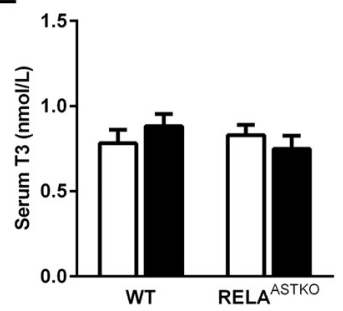

$24 h$

B

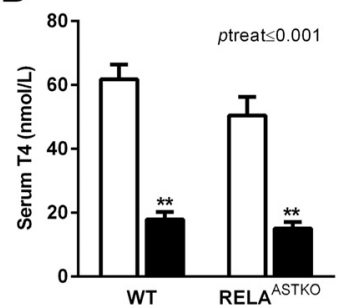

F

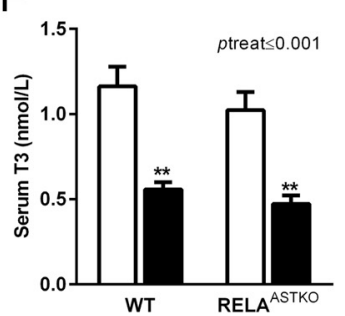

$36 \mathrm{~h}$

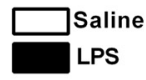

C

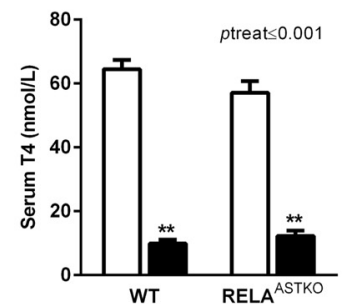

G

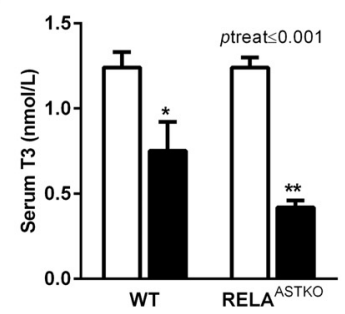

D

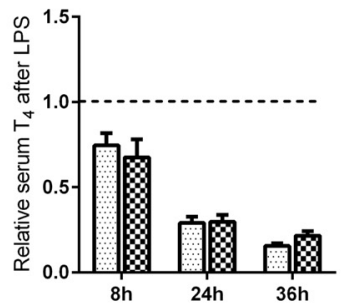

$\mathrm{H}$

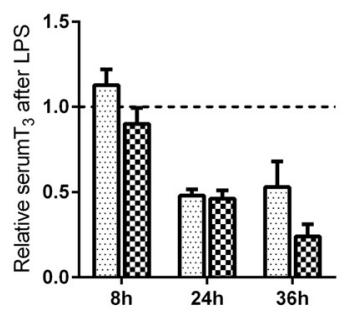

Figure 6. Serum $T_{4}$ and $T_{3}$ concentrations 8 ( $A$ and $\left.E\right), 24$ (B and F), and 36 hours ( $C$ and $G$ ) after LPS or saline injection. White bars represent saline-injected mice, and black bars represent LPS-injected mice (10 $\mu \mathrm{g} / \mathrm{g}$ body weight). In the right panels (D and H), relative responses to LPS injection of WT (dotted bars) and ReIA ASTKO (checked bars) mice are presented. Dotted line represents the saline-treated groups. Mean values \pm SEM are depicted. $P$ values indicate the effect of LPS injection (Ptreat) and genotype (Pgenotype) as evaluated by a two-way ANOVA. Differences between groups ( $n=7-11$ mice per group) were analyzed post hoc with a Tukey's test. ${ }^{*}, P \leq .05 ;{ }^{*}, P \leq .01 ; a, P \leq .05$.

in the initiation of the Dio2 increase. Our studies, however, show an active role of NF- $\kappa$ B in the LPS-induced increase in Dio2 mRNA expression. Because we observed a slight increase in basal Dio2 mRNA expression in the RelA ${ }^{A S T K O}$ mice, we tested whether inhibition of the transcriptional activity of RelA by retaining it in the cytoplasm could lead to enhanced Dio 2 promoter activity in an in vitro experiment. However, we showed no such effect.

\section{TRH in the PVN}

LPS administration decreased Trh expression in the PVN in WT mice, which is in agreement with previous studies of our group (29). In the RelA $A^{A S T K O}$ mice, no decrease in Trh expression was seen after LPS stimulation. However, also, basal Trh expression was significantly reduced in the RelA ${ }^{A S T K O}$ mice. Because we observed simultaneous changes in Dio2 and Trh mRNA expression after 8 hours and did not include earlier time points, we cannot confirm or exclude a causal role of Dio2 (via increased local $\mathrm{T}_{3}$ availability) in the LPS-induced Trh decrease. It should be kept in mind that additional factors, eg, IL-1 $\beta$ and corticosterone, may be involved as well because they are capable of mediating the illness-induced TRH decrease, and play a role during the acute phase of the inflammatory response $(30,31)$.

\section{Pituitary}

Although RelA ${ }^{A S T K O}$ mice had lower basal Trh expression and did not display a drop in Trh expression after LPS administration, neither basal nor LPS-induced pituitary Tsh $\beta$ mRNA differed significantly between RelA ASTKO mice and WT mice. This remarkable observation might be explained by the fact that Trh mRNA levels need not to be indicative for the concentration of the TRH peptide that reaches the pituitary. TRH degrading ectoenzyme (TRH$\mathrm{DE})$, also known as pyroglutamyl peptidase II, is impor-

Table 1. Antibody Table

\begin{tabular}{|c|c|c|c|c|c|}
\hline $\begin{array}{l}\text { Peptide/ } \\
\text { Protein } \\
\text { Target }\end{array}$ & $\begin{array}{l}\text { Antigen } \\
\text { Sequence } \\
\text { (if Known) }\end{array}$ & Name of Antibody & $\begin{array}{l}\text { Manufacturer, Catalog Number, } \\
\text { and/or Name of Individual } \\
\text { Providing the Antibody }\end{array}$ & $\begin{array}{l}\text { Species Raised } \\
\text { (Monoclonal or } \\
\text { Polyclonal) }\end{array}$ & $\begin{array}{l}\text { Dilution } \\
\text { Used }\end{array}$ \\
\hline$\overline{G F P}$ & & GFP tag antibody & Molecular Probes, A-6455 & Rabbit, polyclonal & $1: 500$ \\
\hline Chicken lgY & & Biotinylated goat antichicken IgY & Abcam, ab 6876 & Goat, polyclonal & $1: 500$ \\
\hline Rabbit IgG & & $\begin{array}{l}\text { Goat antirabbit lgG }(\mathrm{H}+\mathrm{L}) \\
\text { secondary antibody, Alexa } \\
\text { Fluor } 488 \text { conjugate }\end{array}$ & Invitrogen, A-11008 & Goat, polyclonal & $1: 1000$ \\
\hline
\end{tabular}


tant for the regulation of TRH concentrations in the extracellular fluid. TRH-DE is present in tanycytes in which it can enhance the breakdown of TRH in the ME through connections of tanycyte end-feet with neuronal projections (32). In hypothyroid rats, $\mathrm{T}_{3}$ and $\mathrm{T}_{4}$ administration leads to TSH suppression, even before the down-regulation of TRH secretion from the PVN via rapid effects on TRH-DE expression in tanycytes. In the case of $\mathrm{T}_{4}$, this requires D2 activity (33). Whether basal levels of TRH-DE are lower in RelA ${ }^{A S T K O}$ mice or TRH-DE is affected by acute inflammation remains to be investigated. Interestingly, acute inflammation has been shown before to have simultaneous effects on hypothalamic and pituitary gene expression (9) which is in accordance with the present findings.

\section{Serum $T_{3}$ and $T_{4}$}

LPS decreased serum TH concentrations in both WT and RelA ${ }^{A S T K O}$ mice. The relatively rapid decrease of $\mathrm{T}_{4}$ cannot be explained by the observed down-regulation of the central part of the HPT axis. LPS induces a variety of proinflammatory cytokines in multiple organs, including the thyroid gland (9). Cytokines have been shown to inhibit iodide uptake, iodothyronine release, and thyroid peroxidase gene expression in cultured human thyrocytes $(34,35)$ and might therefore be responsible for the simultaneous decrease in serum $\mathrm{T}_{4}$ observed in the present study. By contrast, the drop in $\mathrm{T}_{3}$ after 24 hours could be due either to decreased stimulation of the thyroid gland by TSH because $50 \%$ of serum $\mathrm{T}_{3}$ is derived from the thyroid gland in rodents or to increased peripheral clearance of TH by the liver and kidney. To determine whether the effect on serum TH could be delayed, we measured serum TH concentrations in mice 36 hours after LPS or saline injection. However, at this time point, we still did not observe differences between the WT and RelA ${ }^{A S T K O}$ mice.

In conclusion, we show that RelA is essential in the LPS-induced up-regulation of Dio2 in tanycytes and that central changes in the HPT axis during acute inflammation are not the main determinant of decreased serum $\mathrm{TH}$ concentrations observed during acute illness.

\section{Acknowledgments}

This article is dedicated to Professor Falk Weih, who died during the preparation of the manuscript. We are grateful for his contributions to the design of the herein described experiments. We thank Dr R. Schmidt-Ullrich for the NF- $\kappa B-E G F P$ reporter mice. We also thank Elke Meier and Sabine Landmann for their excellent technical assistance. Furthermore, we thank Balasz Gereben for kindly providing us the $\mathrm{hDio} 2$ construct.
Address all correspondence and requests for reprints to: E. M. de Vries, PhD, Department of Endocrinology and Metabolism, Academic Medical Center, University of Amsterdam, F5-169, Meibergdreef 9, 1105 AZ Amsterdam, The Netherlands. E-mail: e.m.devries@amc.uva.nl; or Anita Boelen, PhD, Department of Endocrinology and Metabolism, Academic Medical Center, University of Amsterdam, F5-169, Meibergdreef 9, 1105 AZ Amsterdam, The Netherlands. E-mail: a.boelen@amc.uva.nl.

Disclosure Summary: The authors have nothing to disclose.

\section{References}

1. Van den Berghe G. Novel insights into the neuroendocrinology of critical illness. Eur J Endocrinol. 2000;143:1-13.

2. Boelen A, Kwakkel J, Fliers E. Beyond low plasma T3: local thyroid hormone metabolism during inflammation and infection. Endocr Rev. 2011;32:670-693.

3. Docter R, Krenning EP, de Jong M, Hennemann G. The sick euthyroid syndrome: changes in thyroid hormone serum parameters and hormone metabolism. Clin Endocrinol (Oxf). 1993;39:499-518.

4. Fliers E, Guldenaar SEF, Wiersinga WM, Swaab DF. Decreased hypothalamic thyrotropin-releasing hormone gene expression in patients with nonthyroidal illness. J Clin Endocrinol Metab. 1997;82: 4032-4036.

5. Crantz FR, Silva JE, Larsen PR. An analysis of the sources and quantity of 3,5,3'-triiodothyronine specifically bound to nuclear receptors in rat cerebral cortex and cerebellum. Endocrinology. 1982; 110:367-375.

6. Morte B, Bernal J. Thyroid hormone action: astrocyte-neuron communication. Front Endocrinol (Lausanne). 2014;5:82.

7. Tu HM, Kim SW, Salvatore D, et al. Regional distribution of type 2 thyroxine deiodinase messenger ribonucleic acid in rat hypothalamus and pituitary and its regulation by thyroid hormone. Endocrinology. 1997;138:3359-3368.

8. Alkemade A, Friesema EC, Unmehopa UA, et al. Neuroanatomical pathways for thyroid hormone feedback in the human hypothalamus. J Clin Endocrinol Metab. 2005;90:4322-4334.

9. Boelen A, Kwakkel J, Thijssen-Timmer DC, Alkemade A, Fliers E, Wiersinga WM. Simultaneous changes in central and peripheral components of the hypothalamus-pituitary-thyroid axis in lipopolysaccharide-induced acute illness in mice. J Endocrinol. 2004;182: 315-323.

10. Fekete C, Gereben B, Doleschall M, et al. Lipopolysaccharide induces type 2 iodothyronine deiodinase in the mediobasal hypothalamus: implications for the nonthyroidal illness syndrome. Endocrinology. 2004;145:1649-1655.

11. Fekete C, Sarkar S, Christoffolete MA, Emerson CH, Bianco AC, Lechan RM. Bacterial lipopolysaccharide (LPS)-induced type 2 iodothyronine deiodinase (D2) activation in the mediobasal hypothalamus $(\mathrm{MBH})$ is independent of the LPS-induced fall in serum thyroid hormone levels. Brain Res. 2005;1056:97-99.

12. Sanchez E, Singru PS, Fekete C, Lechan RM. Induction of type 2 iodothyronine deiodinase in the mediobasal hypothalamus by bacterial lipopolysaccharide: role of corticosterone. Endocrinology. 2008;149:2484-2493.

13. Freitas BC, Gereben B, Castillo M, et al. Paracrine signaling by glial cell-derived triiodothyronine activates neuronal gene expression in the rodent brain and human cells. J Clin Invest. 2010;120:22062217.

14. Fonseca TL, Correa-Medina M, Campos MP, et al. Coordination of hypothalamic and pituitary T3 production regulates TSH expression. J Clin Invest. 2013;123:1492-1500.

15. Lamirand A, Ramauge M, Pierre M, Courtin F. Bacterial lipopoly- 
saccharide induces type 2 deiodinase in cultured rat astrocytes. J Endocrinol. 2011;208:183-192.

16. Zeold A, Doleschall M, Haffner MC, et al. Characterization of the nuclear factor $-\kappa \mathrm{B}$ responsiveness of the human dio2 gene. Endocrinology. 2006;147:4419-4429.

17. de Vries EM, Kwakkel J, Eggels L, et al. NF $\kappa$ B signaling is essential for the lipopolysaccharide-induced increase of type 2 deiodinase in tanycytes. Endocrinology. 2014;155:2000-2008.

18. Algul H, Treiber M, Lesina M, et al. Pancreas-specific RelA/p65 truncation increases susceptibility of acini to inflammation-associated cell death following cerulein pancreatitis. J Clin Invest. 2007; 117:1490-1501.

19. Slezak M, Goritz C, Niemiec A, et al. Transgenic mice for conditional gene manipulation in astroglial cells. Glia. 2007;55:15651576.

20. Fauquier T, Chatonnet F, Picou F, et al. Purkinje cells and Bergmann glia are primary targets of the TR $\alpha 1$ thyroid hormone receptor during mouse cerebellum postnatal development. Development. 2014; 141:166-175.

21. Tomann P, Paus R, Millar SE, Scheidereit C, Schmidt-Ullrich R. LHX2 is a direct NF- $\kappa$ B target gene that promotes primary hair follicle placode down-growth. Development. 2016;143(9):15121522.

22. Haenold R, Weih F, Herrmann KH, et al. NF- $\kappa$ B controls axonal regeneration and degeneration through cell-specific balance of RelA and p50 in the adult CNS. J Cell Sci. 2014;127:3052-3065.

23. Mayer S, Muller J, Bauer R, et al. Transporters MCT8 and OATP1C1 maintain murine brain thyroid hormone homeostasis. J Clin Invest. 2014;124:1987-1999.

24. Heuer H, Schafer MKH, O’Donnell D, Walker P, Bauer K. Expression of thyrotropin-releasing hormone receptor 2 (TRH-R2) in the central nervous system of rats. J Comp Neurol. 2000;428:319-336.

25. Wiersinga WM, Chopra IJ. Radioimmunoassays of thyroxine-(T4), 3,5,3'-triiodothyronine (T3), 3,3',5'-triiodothyronine (reverse T3, Rt3), and 3,3'-diiodothyronine (T2). Methods Enzymol. 1982;84: 272-303.
26. Robins SC, Stewart I, McNay DE, et al. $\alpha$-Tanycytes of the adult hypothalamic third ventricle include distinct populations of FGFresponsive neural progenitors. Nat Commun. 2013;4:2049.

27. Napetschnig J, Wu H. Molecular basis of NF- $\kappa \mathrm{B}$ signaling. Annu Rev Biophys. 2013;42:443-468.

28. Sanchez E, Singru PS, Wittmann G, et al. Contribution of TNF- $\alpha$ and nuclear factor- $\kappa \mathrm{B}$ signaling to type 2 iodothyronine deiodinase activation in the mediobasal hypothalamus after lipopolysaccharide administration. Endocrinology. 2010;151:3827-3835.

29. Boelen A, Kwakkel J, Chassande O, Fliers E. Thyroid hormone receptor beta mediates acute illness-induced alterations in central thyroid hormone metabolism. J Neuroendocrinol. 2009;21:465472 .

30. Kakucska I, Romero LI, Clark BD, et al. Suppression of thyrotropinreleasing-hormone gene-expression by interleukin-1- $\beta$ in the ratimplications for nonthyroidal illness. Neuroendocrinology. 1994; 59:129-137.

31. Kakucska I, Qi YP, Lechan RM. Changes in adrenal status affect hypothalamic thyrotropin-releasing-hormone gene-expression in parallel with corticotrophin-releasing hormone. Endocrinology. 1995;136:2795-2802.

32. Sanchez E, Vargas MA, Singru PS, et al. Tanycyte pyroglutamyl peptidase II contributes to regulation of the hypothalamic-pituitarythyroid axis through glial-axonal associations in the median eminence. Endocrinology. 2009;150:2283-2291.

33. Marsili A, Sanchez E, Singru P, et al. Thyroxine-induced expression of pyroglutamyl peptidase II and inhibition of TSH release precedes suppression of TRH mRNA and requires type 2 deiodinase. J Endocrinol. 2011;211:73-78.

34. Sato K, Satoh T, Shizume K, et al. Inhibition of I-125 organification and thyroid-hormone release by interleukin-1, tumor necrosis factor- $\alpha$, and interferon- $\gamma$ in human thyrocytes in suspension-culture. J Clin Endocrinol Metab. 1990;70:1735-1743.

35. Tominaga T, Yamashita S, Nagayama Y, et al. Interleukin-6 inhibits human thyroid peroxidase gene-expression. Acta Endocrinol. 1991; 124:290-294. 